\title{
CENTRAL MECHANISMS OF VOMITING RELATED TO CATECHOLAMINE RESPONSE: ANAESTHETIC IMPLICATION
}

\author{
LEONARD C. JeNKINS, B.A., M.D., C.M., F.R.C.P. (C) * AND \\ DOUGLas LaHaY, M.D., F.R.C.P. (c) †
}

\begin{abstract}
Vomiting IN ASSOCIATION with anaesthesia continues to be a major problem. A vomiting centre ${ }^{1}$ and a chemoreceptor trigger zone ${ }^{2}$ have been identified, but their relationship to the mechanism of anaesthetic-induced vomiting remains to be clarified, ${ }^{3-5}$ An adrenergic mechanism is suggested by the observations that some general anaesthetic agents increase circulating catecholamine levels, for example, diethyl ether ${ }^{6}$ and cyclopropane, ${ }^{7}$ and these agents are associated with a high incidence of post-operative vomiting. ${ }^{8,9}$ Other general anaesthetic agents, such as halothane ${ }^{10}$ and methoxyflurane, ${ }^{11}$ tend to act as adrenergic blockers, do not increase circulating catecholamine levels and are associated with a reduced incidence of vomiting. ${ }^{12,13}$
\end{abstract}

\section{METHODS}

To evaluate this relationship, the catecholamines norepinephrine, epinephrine, and isopropylnorepinephrine and the alpha and beta adrenergic blocking agents phentolamine and propranolol were placed at selected cNs sites (Table I). They were given through permanent indwelling stereotaxically placed stainless steel bipolar recording cannula electrodes, in a series of fifty non-anaesthetized, unrestrained, intact, and otherwise drug free cats. Implantation followed techniques modified from Yamaguchi, Ling, and Marczynski, ${ }^{14}$ using the co-ordinates of Jasper's Stereotaxic Atlas, ${ }^{15}$ and Kopf stereotaxic instrument for placement. ${ }^{16}$ The intraventricular placement of cannulae has been described recently (Archer \& Jenkins ${ }^{17}$ ).

Position of the intraventricular cannula was assured by the free flow of cerebrospinal fluid on placement, and by radiographic analysis. The position of the chemitrodes was later verified by post-mortem histological examination of the brain.

Three weeks after preparation, the drug-free and healthy cats were placed, unrestrained, in a viewing box. Behaviour was observed from a darkened and quiet room through a one-way mirror on the door of the viewing chamber. The Canon recording plug fixed in the acrylic supracranial crown was connected by a light and mobile cable to the EEG machine (Grass). Following control tracings, the animals were given selected drugs through the recording cannula electrodes.

\footnotetext{
"Professor and Head, Department of Anaesthesia, University of British Columbia, Vancouver 9, B.C.

†Teaching and Research Fellow, Department of Anaesthesia, University of British Columbia, Vancouver 9, B.C.
} 
TABLE I

CNS Sites Injected with Catecholamines

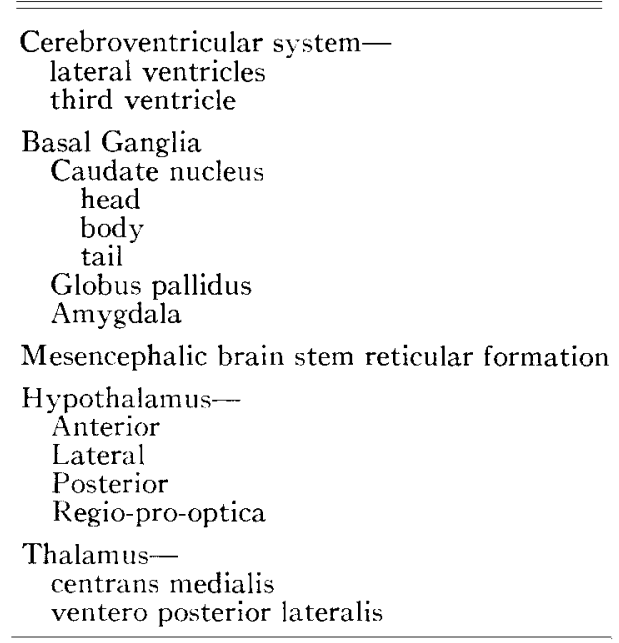

TABLE II

Minimum Drug Dosage of Catecholamines and Alpha and Beta Blockers that Produced a Consistent Effect

\begin{tabular}{lc}
\hline \multicolumn{1}{c}{ Drug } & $\begin{array}{c}\text { Dose } \\
(\mu \mathrm{g} \text { per kg) }\end{array}$ \\
\hline Norepinephrine & 100 \\
Epinephrine & 30 \\
Isopropylnorepinephrine & 0.015 \\
Phentolamine & 100 \\
Propanolol & 25 \\
\hline
\end{tabular}

Behavioural responses were then serially correlated with EEG and subcortical electrical changes.

Drug dosage was determined as the minimum dose which would produce a consistent effect or provide a consistent block. The dosage schedule thus determined is summarized in Table II.

When adrenergic blocking agents were used, they were given five minutes prior to the challenge dose of the catecholamines through the same cannula electrode. Control injections of saline were made in the same cats using identical volumes, $\mathrm{pH}$, and osmolality. Each cat served as its own control for each drug and in all, fifty cats were used for each drug. In all instances a minimum recovery period of 72 hours was allowed before the same animal was used again.

\section{Results}

Typical behavioural responses (vomiting) and associated EEG changes (activation, deactivation) are illustrated in Figures 1 and 2.

Figure 1 shows the EEG changes following norepinephrine injection into the 


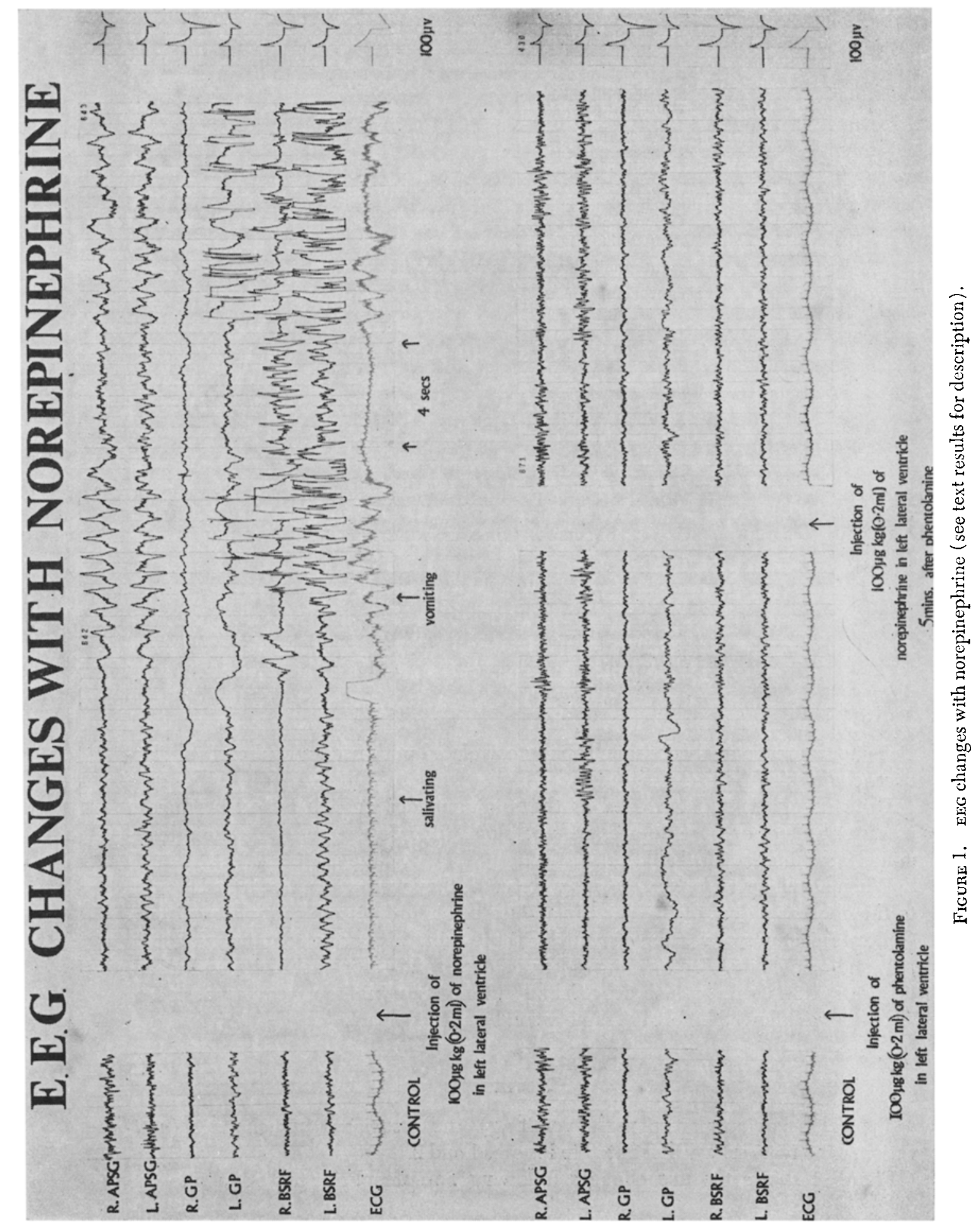




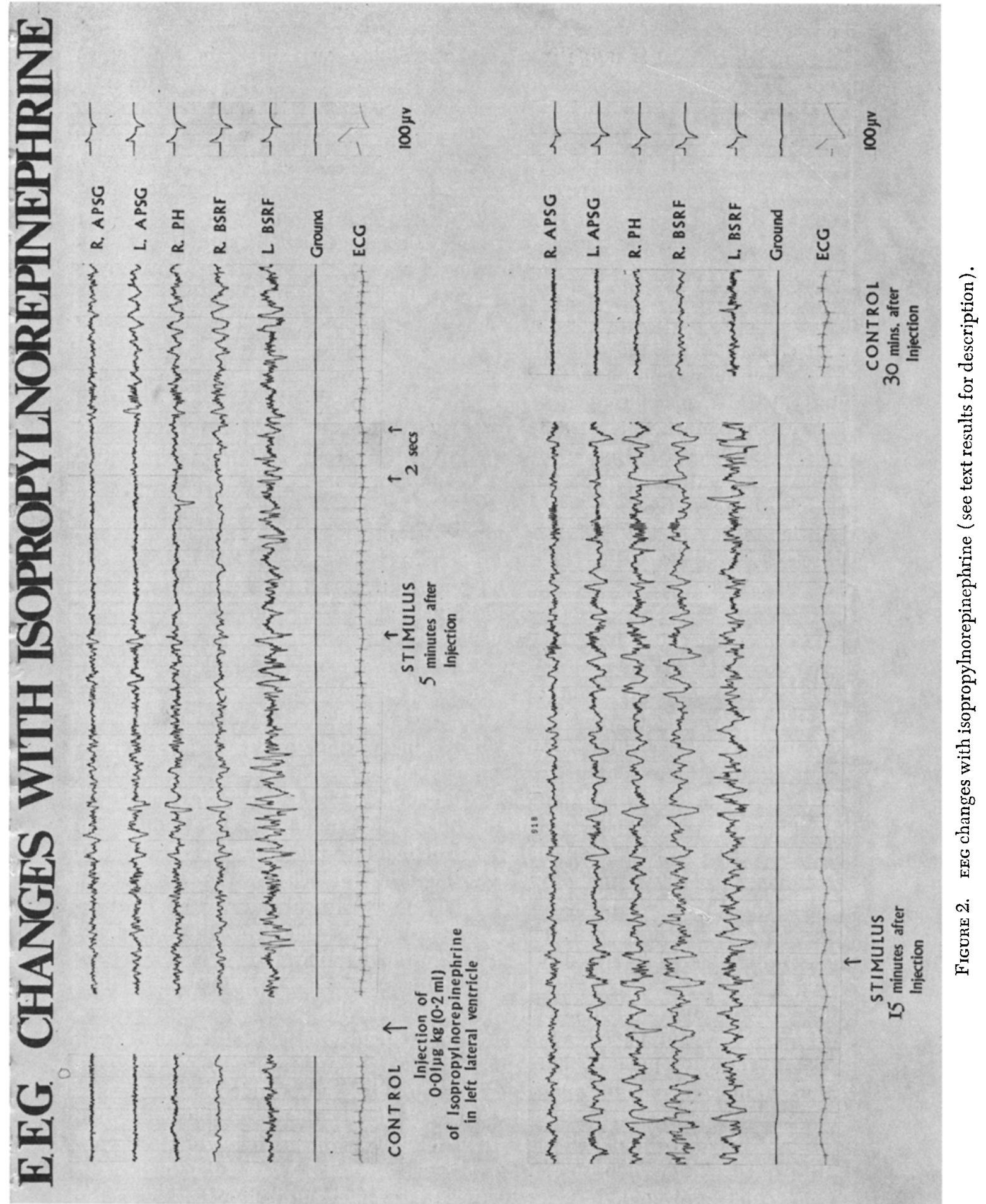


lateral ventricle, and relates these to the observed vomiting response. On the left, the control pattern is seen with electrode placement indicated from above down: right and left cortical (RAPSG, LAPSG), globus pallidus (GP), and brain stem (BSRF) leads. The ECG was taken, simultaneously, from shoulder leads to provide an early indication of possible systemic absorption. Systemic arterial blood pressure was recorded separately. Norepinephrine, $100 \mu \mathrm{g} / \mathrm{kg}$ in a $0.2-\mathrm{ml}$ volume, was then injected into the left lateral ventricle. Within five minutes or less, the EEG pattern showed increased frequency and decreased amplitude, typical of an activation pattern, followed in sequence by salivation and vomiting which lasted from 10 to 15 minutes. Much of the tracing over this period is artifactual due to the violent movements of vomiting. The lower tracing in Figure 1 is from a similar cat given $100 \mu \mathrm{g}$ of phentolamine, by the same route, five minutes prior to the challenge dose of norepinephrine and illustrates the blocked response - with neither vomiting or EEG change obtained.

These effects were seen in all fifty cats. Similar responses were seen following intraventricular injection of epinephrine, except that the EEG showed a delayed deactivation pattern following the vomiting. This may be a $\beta$-adrenergic effect since the delayed deactivation with epinephrine is not seen following propranolol blockade. As with norepinephrine, the vomiting response could be prevented by prior phentolamine blockade.

An interesting finding following intraventricular injection of isopropylnorepinephrine is seen in Figure 2. The control pattern is shown on the left and electrode placement is indicated on the right; bilateral cortical and brain stem leads and a right posterior hypothalamus (RPH) electrode were used in this instance. Isopropylnorepinephrine, $0.015 \mu \mathrm{g} / \mathrm{kg}$ in $0.2-\mathrm{ml}$ volume, was given, and within five minutes or less, a pronounced deactivation pattern was evident. Following a stimulus (auditory, vibratory, light, or electrical), the pattern altered to one of activation, reverting back to deactivation after six seconds. This arousal to an activated pattern could not be obtained 15 minutes after injection following a similar stimulus and, in all, the deactivation pattern and associated behavioural sedation resulting from the isopropylnorepinephrine lasted about 30 minutes before gradually returning to the control pattern. An intriguing side question comes to mind. Can anaesthesia (at least sedation and EEG deactivation) be induced by central $\beta$ adrenergic activity? When isopropylnorepinephrine is blocked with prior injection of propranolol there is no behavioural sedation or electrical correlate of deactivation. Use of the blocking agents alone produced neither vomiting nor EEG changes.

The results are summarized in Table III which demonstrates that a vomiting response follows intraventricular injection of a catecholamine with $\alpha$-stimulating properties, whether or not $\beta$ activity is additionally present (norepinephrine, epinephrine). Vomiting never follows intraventricular injections of a drug with predominantly $\beta$-stimulating properties (isopropylnorepinephrine) nor with injection of either $\alpha$ (phentolamine) or $\beta$ (propranolol) adrenergic blocking agents given alone. Control studies have shown that the vomiting is not a volume, $\mathrm{pH}$, or osmolality effect. The vomiting response following an $\alpha$-stimulating drug appears to be specific and consistent in four respects:

(a) It can be prevented by prior administration of a drug with $\alpha$-blocking activity (phentolamine) but not by a drug with $\beta$-blocking activity (propranolol). 
TABIE III

Lateral and Thiro Ventricle Injection of Catecholamines and Adrenergic Blockers

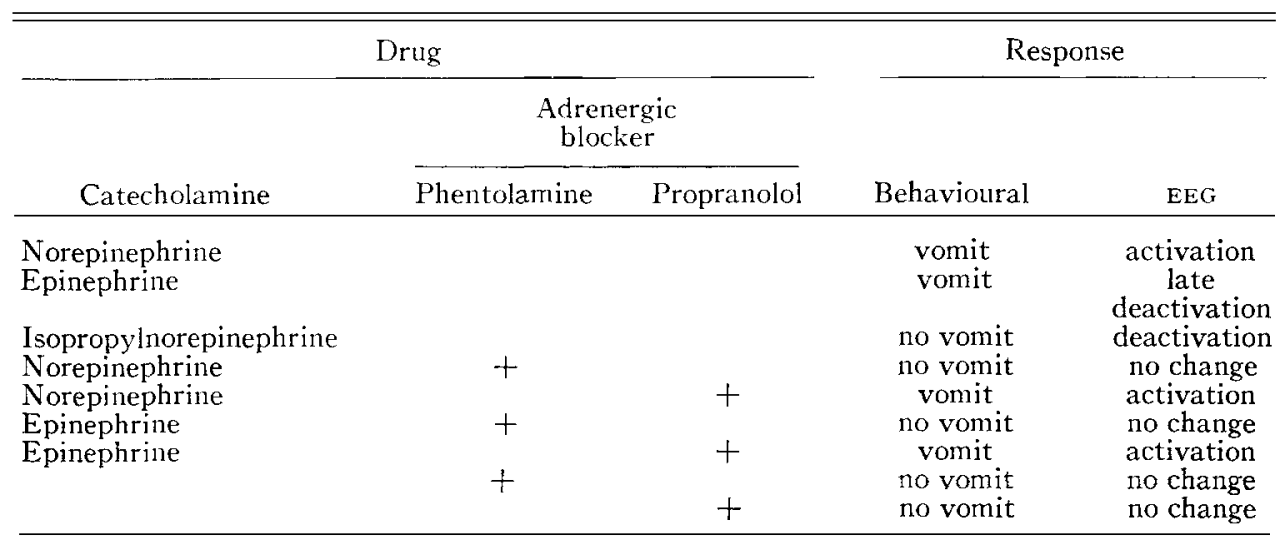

(b) Vomiting only follows intraventricular injection and is never seen following injection into any of the other tested cNs sites.

(c) Site and latency of response are also consistent in that vomiting occurs much earlier if the $\alpha$-stimulating catecholamines are injected into the third ventricle than when they are given by the lateral ventricular route.

(d) EKG and systemic arterial blood pressure is not altered prior to an evoked vomiting response. Catecholamine arterial levels were not changed following intraventricular injection of drugs.

EEG changes are associated with the behavioural vomiting response. Activation accompanics the vomiting response produced by an $\alpha$-stimulating catecholamine (norepinephrine). Deactivation is seen in each instance following a $\beta$-stimulating catecholamine (isopropylnorepinephrine) and occurs after either extraventricular or intraventricular injection. If the catccholamine has both $\alpha$-and $\beta$-stimulating properties, the initial EEG response is activation (in association with the vomiting) which later alters to a deactivation, following the cessation of vomiting.

Thus, $\alpha$-stimulation, vomiting, and activation are associated, as are $\beta$-stimulation, absence of vomiting, and deactivation.

\section{Discussion}

These findings are not at variance with what is known of central mechanisms of vomiting and may serve to clarify existing concepts. ${ }^{2,18}$

Borison and Wang' have described a chemoreceptor trigger zone (CTz) which lies superficially in the wall of the 4 th ventricle near the obex. This area is more drug permeable than the underlying medulla. ${ }^{19}$ It acts as a central chemoreceptor for various agents ${ }^{20}$ and is connected by afferents to a deeper structure, the vomiting centre, which, on stimulation, co-ordinates the multiple motor activities of the vomiting responses. Our work suggests that a central mechanism of vomiting may involve an $\alpha$-adrenergic mechanism. The known superficial anatomy of the CTz correlates well with the findings that vomiting only occurs following intraventricular injection, and that this response shows less of a latent period if the injection is made in the 3rd ventricle, an area closer to the cTz than the lateral ventricle. These 
findings are more suggestive of a surface phenomenon than an effect from systemic absorption.

Indirect evidence against a systemic effect includes:

(a) The lack of an associated ExG or systemic arterial blood pressure change prior to or during an evoked vomiting response.

(b) The failure to produce vomiting by injection into other cNs sites.

Carr and Moore ${ }^{21}$ have recently shown, by radioactive tag, that norepinephrine and its metabolic products can be distributed to ventricular surfaces adjacent to CTZ areas, after its administration into the cerebroventricular system of the cat.

Our direct evidence against a systemic effect was obtained by accurately measuring circulating catecholamine levels before and after intraventricular injection of the $\alpha$-stimulating and $\beta$-stimulating drugs. These levels remained unaltered (as did the systemic (femoral-aortic) arterial blood pressure), so that systemic absorption is not evident during the period when vomiting and EEG changes are observed.

To relate these concepts of vomiting to anaesthesia, further work will involve quantitative measurement of CSF and peripheral circulating catecholamine levels and their threshold inter-relationships during anaesthesia with various anaesthetic agents. These will be given by both standard inhalation techniques and by the recently described technique of intracerebral gas diffusion..$^{22}$ More precise localization of site of action will be determined by fluores $\operatorname{cin}^{23}$ and radioactively tagged catecholamine studies. ${ }^{21}$

\section{Conclusion}

These results, in cats, suggest that a central mechanism of vomiting may involve an $\alpha$-adrenergic link, accessible via the cerebroventricular system.

\section{RÉSUMÉ}

L'injection intraventriculaire d'une catécholamine avec des propriétés $\alpha$ stimulantes a produit comme réponse : des vomissements, que soit présente ou non une activité $\beta$ additionnelle (norépinéphrine, épinéphrine). Des injections intraventriculaires de substances aux propriétés $\beta$ stimulantes (isopropylnérépinéphrine) ou de substances, données seules, et contenant soit des bloqueurs $\beta$ (propronolol) n'ont jamais produit comme réponse : des vomissements. Des études de contrôle ont démontré que les vomissements n'étaient pas un effet dû au volume, au $\mathrm{pH}$, ou à l'osmolarité. Le vomissement en réponse à l'administration d'une substance $\alpha$ stimulatrice nous semble spécifique et consistant sous plusieurs aspects : il peut être évité par l'injection préalable d'un bloqueur $\alpha$ (phentolamine) mais non pas par l'injection d'un bloqueur $\beta$ (propanolol); les vomissements sont survenus seulement après l'injection intraventriculaire et jamais après les mêmes injections dans aucun des autres endroits du système nerveux central; l'endroit et le délai de réponse ont aussi été consistants en ceci que les vomissements sont apparus beaucoup plus tôt si les catécholamines $\alpha$ stimulantes étaient injectées dans le 3e ventricule plutôt que par la route du ventricule latéral; l'Ekg et la pression artérielle systémique n'étaient pas modifiés par la provocation d'un vomissement. Les taux artériels de 
catécholamine ne changeaient pas après l'injection intraventriculaire de la substance.

\section{REFERENCES}

1. Best, H. C., \& Taylon, N. B. The Physiological Basis of Medical Practice, 5th Edition, Williams and Wilkins Co, Baltimore (1950).

2. Borison, H. L. \& Wang, S. C. Physiology and pharmacology of vomiting. Pharm. Revs., 5: $193(1953)$.

3. Brown, H. G. Mechanism of vomiting in association with general anaesthesia. Brit. J. Anaesth., 35: 136 (1963).

4. Hayama, T. \& Ogula, Y. Site of emetic action of tetrodoxin in the dog. J. Pharmacol. \& Exper. Therap. 139: 94-96 (1963).

5. Bannister, W. K. \& Sattilaro, Capt. A. J. Vomiting and aspiration during anaesthesia. Anesthesiology, 23: 251 (1962).

6. Price, H. L. Circulatory adrenaline and noradrenaline during diethyl ether anaesthesia in Man. Clin. Sci., 16: 377-387 (1957).

7. Price, H. L.; Jones, R. E.; Deutsch, S.; \& Linde, H. W. Ventricular function and autonomic nervous activity during cyclopropane anaesthesia in man. J. Clin. Invest., 41: 604610 (1962).

8. Evans, F. T., \& Gray, T. C. General Anaesthesia, 1st Edition, Butterworth and Co. Ltd., London (1959) Vol. 1, p.336.

9. Dripps, R. D.; Echenhoff, J. E.; \& Vandam, L. D. Anaesthesia. W. B. Saunders Company, Philadelphia (1961) 2nd Ed. p.79.

10. BLACK, G. W. A review of the pharmacology of halothane. Brit. J. Anaesth., 37: 688 (1965).

11. McIntyre, J. W. R., \& Gain, E. A. Methoxyflurane. Canad. Anaesth. Soc. J., 9: 319 (1962).

12. Haumann, J. LeR., \& Foster, P. A. The antiemetic effect of halothane. Brit. J. Anaesth., 35: 114 (1963).

13. Chang, J.; Macartney, H. H.; \& Graves, H. B. Clinical experience with Fluothane: A new non-explosive agent. Canad. Anaesth. Soc. J., 4: 187 (1957).

14. Yamaguchi, N.; LING, G. M.; \& MARCZYNSKI, T. J. Recruiting responses observed during wakefulness and sleep in unanaesthetized chronic cats. Electroencephalog. \& Clin. Neurophysiol. 17: 246 (1964).

15. Jasper, H. H. \& AJMONe-Matsan, C. A stereotaxic atlas of the diencephalon of the cat. Publ. Nat. Res. Council of Canada (1956).

16. David Kopf Instruments (1404, 1255, 1455, 1755) 7324 Elmo St., P.O. Box 636, Tujunga, California, 91042.

17. Archer, L. T. \& Jenkins, L. C. Experimental cNs studies related to anaesthesia: Clinical implications (v) The effects and distribution of cerebral intraventricular microinjection of pentobarbital. Canad. Anaesth. Soc. J. (In Press).

18. Thatcher, R. A., \& Weiss, S. Studies on vomiting. J. Pharmacol. \& Exper. Therap., 22: 139 (1923).

19. Ganong, W. F. Review of Medical Physiology, Lange Medical Publications, Los Altos, California (1967) p.167.

20. Marczynski, T. J. Topical application of drugs to subcortical brain structures and selected aspects of electrical stimulation. Reviews of Physiology, Binchemistry and Experimental Pharmacology, Springer-Verlag, Berlin, Heidelberg ( 1967 ) p.93.

21. Carr, L. A. \& Moore, K. E. Distribution and metabolism of norepinephrine after its administration into the cerebroventricular system of the cat. Biochemical Pharmacol., 18: 1907-1918 (Aug., 1969).

22. Folmman, J. Intracerebral gas anaesthesia by diffusion through silicone rubber. Anesthesiology, 29: 419-425 (1968).

23. Routtenberg, A.; Sladek, J.; \& Bondareff, W. Histochemical fluorescence after application of neurochemicals to caudate nucleus and septal area in vivo. Science, 161: 272274 (1968). 